\title{
Endoscopic extraction of a chopstick impacted in the gastric antrum
}

A 36-year-old woman was referred for moderate epigastric pain following intentional ingestion of a $26-\mathrm{cm}$ chopstick; this was attributed to a family disturbance 7 days earlier. As there were no systemic symptoms of peritonitis or significant bleeding, an emergency upper endoscopy was performed. The examination showed the lower end of the chopstick impacted in the gastric antrum ( $\triangleright$ Fig.1a) while the upper end was proximal to the gastric fundus. An open snare was initially maneuvered to grasp the chopstick from the upper end, but this failed after repeated attempts. Then we used a closed snare to slightly lift up the chopstick, and successfully grasped the upper end of the chopstick ( $\triangleright$ Fig. 1 b). After adjusting the direction of the chopstick, we easily extracted it with withdrawal of the scope ( $\triangleright$ Fig.1 c). An area showing hyperemia and swelling without perforation remained ( $\triangleright$ Fig. $\mathbf{1 d}$; - Video 1). The patient returned to her normal diet on the first postoperative day with no discomfort.

Most ingested foreign bodies can pass spontaneously, but endoscopic interventions are frequently needed in cases of intentional ingestion [1]. It is also reported that foreign bodies longer than $6 \mathrm{~cm}$, such as eating utensils, have difficulty in passing through the stomach [1]. Snares are often used to grasp such long objects [2]. Our experience in extracting such long columnar foreign bodies suggests that grasping them less than $1 \mathrm{~cm}$ from their upper end and adjusting them to be parallel to the lumen are helpful to avoid their getting stuck or causing damage to the gastrointestinal tract.

Endoscopy_UCTN_Code_TTT_1AO_2AL

Competing interests

None
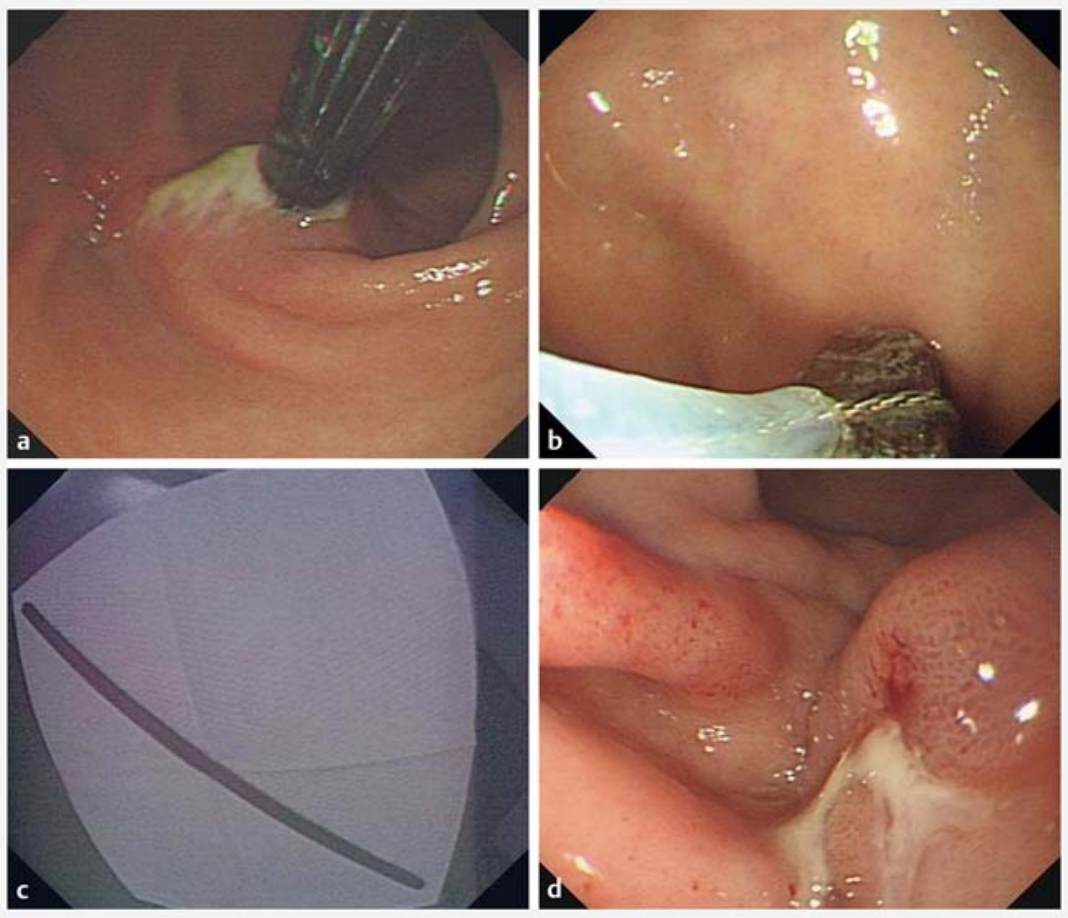

- Fig. 1 a A chopstick impacted in the gastric antrum. $\mathbf{b}$ The chopstick is grasped with a snare. $\mathbf{c}$ The extracted long chopstick. $\mathbf{d}$ An area of hyperemia and swelling remained.
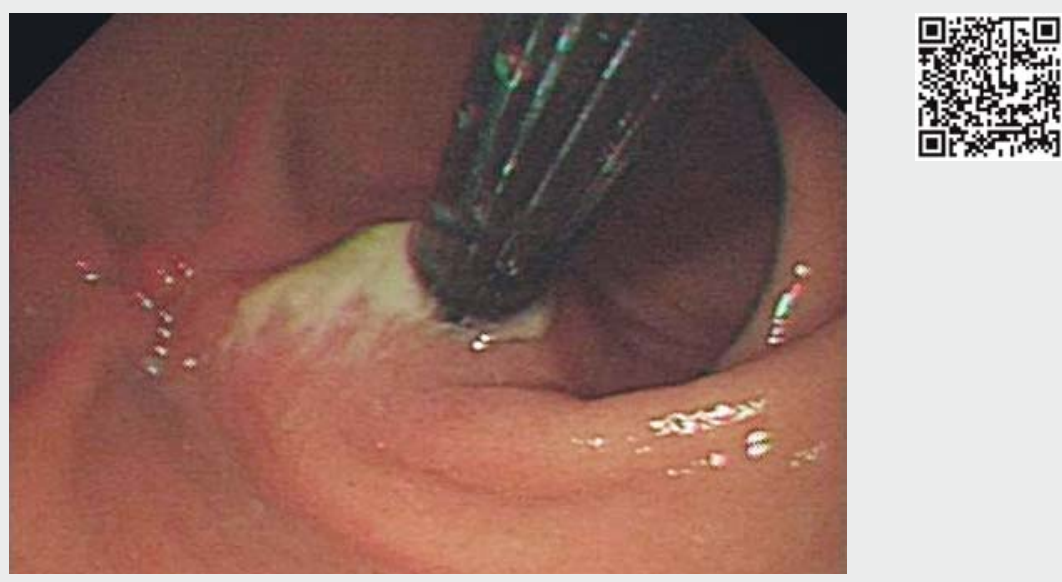

$\checkmark$ Video 1 Endoscopic extraction of a chopstick impacted in the gastric antrum. 
The Authors

Liansong Ye*, Honglin Chen", Chuncheng Wu, Wei Liu, Yuhang Zhang, Chuanhui Li, Bing Hu Department of Gastroenterology, West China

Hospital, Sichuan University, Chengdu, China

Corresponding author

\section{Bing Hu, MD}

No. 37, Guo Xue Xiang, Wu Hou District, Cheng Du City, Sichuan Province, China 610041

Fax: +86-028-85423387

hubingnj@163.com

* Co-first authors

\section{Acknowledgment}

We acknowledge the support of the Endoscopy Center of Sichuan University West China Hospital, Chengdu, China.

\section{References}

[1] Palta R, Sahota A, Bemarki A et al. Foreignbody ingestion: characteristics and outcomes in a lower socioeconomic population with predominantly intentional ingestion. Gastrointest Endosc 2009; 69: 426-433

[2] Ikenberry SO, Jue TL, Anderson MA et al. Management of ingested foreign bodies and food impactions. Gastrointest Endosc 2011; 73: $1085-1091$

\section{Bibliography}

DOI https://doi.org/10.1055/s-0043-111716

Published online: 14.6.2017

Endoscopy 2017; 49: E200-E201

(c) Georg Thieme Verlag KG

Stuttgart · New York

ISSN 0013-726X
ENDOSCOPY E-VIDEOS

https://eref.thieme.de/e-videos

口回回 Endoscopy E-Videos is a free access online section, reporting 田: on interesting cases and new techniques in gastroenterological endoscopy. All papers include a high quality video and all contributions are freely accessible online.

This section has its own submission website at https://mc.manuscriptcentral.com/e-videos 